\title{
COVID-19 associated mucormycosis in head and neck region of children during current pandemic: Our experiences
}

\author{
Santosh K. Swain'1, Pragnya P. Jena², Smarita Lenka' \\ 'Department of Otorhinolaryngology, IMS and SUM hospital, Siksha "O" Anusandhan University, Odisha, India \\ 2Department of Microbiology, IMS and SUM hospital, Siksha "O" Anusandhan University, Odisha, India
}

\section{ABSTRACT}

\begin{abstract}
Aim: Mucormycosis is a rare but severe fungal infection, particularly found in immunocompromised patients. Currently this dreaded mucormycosis is rising among COVID-19 paediatric patients during their treatment period or after their discharge from hospital. It is also called as black fungus. The aim of this study is to evaluate the COVID-19 associated mucormycosis (CAM) in head and neck region of the paediatric patients with its clinical manifestations and management.

Material and methods: This is a descriptive and prospective study of paediatric patients with COVID-19 associated mucormycosis (CAM) carried out at a postgraduate teaching hospital. This study was conducted between March 2020 to April 2021. Patient profile such as age, sex, comorbidities, clinical presentations, diagnosis and treatment of the CAM were analysed. There were 12 paediatric patients of CAM were enrolled in this study.

Results: Out of 12 paediatric patients of CAM, there were eight male and four female patients, aged from 3 years to 16 years. Out of the 12 patients, 3 were diabetic (25\%). Three patients (25\%) were taking prolonged systemic steroids with prolonged hospital ICU stay. Two children $(16.66 \%)$ were under chemotherapy for acute leukaemia. The common clinical symptoms were facial swelling, facial pain, nasal block and nasal discharge. Diagnosis was confirmed by histological examination. All were treated with endoscopic surgical debridement and amphotericin B. Two patients were passed away; one was due to cerebral involvement and another was due to respiratory failure by pneumonia.

Conclusions: Early identification and prompt treatment in paediatric patients with CAM are required. Aggressive endoscopic surgical debridement for local control and appropriate systemic antifungal treatment will help to improve the prognosis and survival of the patients.
\end{abstract}

KEY WORDS:

COVID-19 associated mucormycosis, pediatric patient, endoscopic surgical debridement, amphotericin B.

\section{INTRODUCTION}

Mucormycosis is a dreaded fungal infection with characteristic feature of angioinvasion [1]. It is caused by a fungus belong to the order Mucorales of the class Zygomycetes. This fungus is saprophytic in nature and often found in soil, vegetables, respiratory and digestive system of the human. Rhizopus species (approximately
44\%) and Mucor species (approximately 15\%) are most commonly seen in the mucormycosis [1]. The critical ill COVID-19 patients those were admitted to the intensive care unit (ICU) and required mechanical ventilation or had prolonged duration hospital stays and those are taking systemic steroid for prolonged period are likely to get co-fungal infections such as mucormycosis, called COVID-19 associated mucormycosis (CAM) [2, 3].

\section{ADDRESS FOR CORRESPONDENCE:}

Santosh K. Swain, Department of Otorhinolaryngology, IMS and SUM hospital, Siksha "O” Anusandhan

University, K8, Kalinganagar,Bhubaneswar-751003, Odisha, India, e-mail: santoshvoltaire@yahoo.co.in 
The histopathological study, direct, microscopy and culture from the clinical samples are the important diagnostic modalities for the CAM [4]. The CAM in children is less frequently documented in the literature. The objective of this study is to analyse the detail of clinical profile and management of the CAM in children.

\section{MATERIAL AND METHODS}

\section{PATIENTS}

This is a prospective study conducted in 12 children of either sex in the age group of 3 to 16 years suffering from CAM during March 2020 to April 2021. Our Institutional Ethics Committee (IEC) approved this study with the reference number IEC/IMS/SOA/13/06.03.2020. COVID-19 paediatric patients infected with mucormycosis during treatment period at COVID hospital or after discharge from the COVID hospital were included in this study. All of them reverse transcription polymerase (RTPCR) positive for viral RNA and diagnosed COVID-19 at the time of hospitalization. The COVID-19 paediatric patients without mucormycosis or Non-COVID-19 paediatric patients with mucormycosis were excluded from this study. Patients of CAM older than 18 years of age were excluded in this study.

\section{METHODS}

For each registered child, the detail clinical record included demographic data, predisposing factors, clinical presentations, investigations, treatment and treatment outcome. The clinical presentations, diagnosis, treatment and outcome of the CAM among children were studied.

\section{DIAGNOSIS OF MUCORMYCOSIS}

All the enrolled paediatric patients underwent diagnostic nasal endoscopy for assessing the bilateral nasal cavity and nasopharynx. Direct microscopic examination with $10 \%$ potassium hydroxide $(\mathrm{KOH})$ was utilised for confirming the broad aseptate hyphae. Culture was done in Sabouraud dextrose agar, Sabouraud dextrose with chloramphenicol agar and yeast extract agar. Biopsy was done in all cases and the histopathological study included haematoxylin and eosin, periodic acid-Schiff and Grocott-Gomori's methenamine silver (GMS) staining. Computed tomography (CT) scan of the nose and paranasal sinus and magnetic resonance imaging (MRI) done to find out the extent of the diseases into orbit and brain. During nasal endoscopy, the tissue from the nasal cavity sent for microscopy, culture and histopathological examination showing broad non-septate hyphae with $90^{\circ}$ branching (Figure 1). Ophthalmological and neurological consultations were done in all cases to find loss of vision or not and neurological involvement. There were 12 COVID-19 paediatric patients with mucormycosis enrolled in this study. Out of 12 patients, 7 was already discharged from COVID hospital attached to our Medical college and rest 5 were diagnosed during the treatment at COVID hospital. Biopsy was taken from all the cases, which showed the picture of mucormycosis with some foci of non-septate fungal hyphae with right-angled hyphae branches. All paediatric patients underwent endoscopic debridement of the mucormycosis along with exenteration of the orbit in two cases, followed by parenteral infusion amphotericin $B(1-1.5 \mathrm{mg} / \mathrm{kg} /$ day $)$ and total dose of 2.5-3 gm.

\section{STATISTICAL METHODS}

SPSS Statistics for Windows, version 20, was used for all statistical analyses (IBM-SPSS Inc., Chicago, IL, USA).

\section{RESULTS}

There were 12 paediatric patients of CAM were enrolled in this study with age range from 3 to 16 years. Out of 12 paediatric patients of mucormycosis, there were 8 boys (66.66\%) and 4 girls (33.33\%) with male to female ratio of 2:1. Out of the 12 patients, 3 (25\%) were diabetic. All the 3 diabetic mellitus patients were under treatment with oral hypoglycaemic agents/insulins regularly, but their blood sugar was poorly controlled. Two children $(16.66 \%)$ were diagnosed with acute leukaemia, three patients (25\%) were taking high dose of steroids and one (8.33\%) had taken tocilizumab during the treatment of the COVID-19 infection. Out of the 12 patients, $6(50 \%)$ were diagnosed with sinonasal mucormycosis, $4(33.33 \%)$ had rhino-orbital mucormycosis, 1 (8.33\%) had oronasal (nasal and palatal involvement) type of the mucormycosis and $1(8.33 \%)$ had rhino-orbital-cerebral mucormycosis (Table 1). The children presented with foul smell nasal discharge, nasal block, headache, eye pain, proptosis, facial swelling and blurring of vision or loss of vision. All the 12 paediatric patients presented with foul smelling nasal discharge and nasal block. Out of the 12 patients, 7 (58.33\%) of them were presenting with facial pain but $6(50 \%)$ were presenting with facial swelling (Figure 2). Three (25\%) children were presenting with headache, two (16.66\%) had proptosis, one (8.33\%) had nasal septal perforation and one (8.33\%) had altered sensorium. Before the surgical debridement, the nasal swab sent for $\mathrm{KOH}$ mount where all patients showed aseptate hyphae. Culture of the nasal discharge showed Rhizopus oryzae in nine patients and the rest showed no growth. All patients underwent endoscopic surgical debridement under general anaesthesia. All the patients were also administered intravenous infusion of amphotericin B. In this study, out of two patients (16.66\%) of death, one was due to cerebral involvement and another case died because of the respiratory failure by 
TABLE 1. Clinical profile of the COVID-19 associated mucormycosis pediatric patients

\begin{tabular}{|c|c|c|c|c|c|c|c|}
\hline $\begin{array}{l}\text { Patient's } \\
\text { serial }\end{array}$ & $\begin{array}{l}\text { Age } \\
\text { (years) }\end{array}$ & Sex & Affected part & Clinical presentations & $\begin{array}{l}\text { Co-morbid } \\
\text { diseases }\end{array}$ & Treatment & Outcome \\
\hline 1 & 3 & $M$ & Sinonasal & $\begin{array}{l}\text { Facial swelling, facial pain, } \\
\text { nasal discharge,nasal block }\end{array}$ & $\begin{array}{l}\text { Acute lymphoblastic } \\
\text { leukemia }\end{array}$ & $\begin{array}{l}\text { Endoscopic surgical } \\
\text { debridement plus } \\
\text { amphotericin B }\end{array}$ & Cured \\
\hline 2 & 5 & $\mathrm{~F}$ & Naso-orbital & $\begin{array}{c}\text { Facial pain, nasal block, nasal } \\
\text { discharge, facial swelling, } \\
\text { nasal septal perforation }\end{array}$ & $\begin{array}{c}\text { Prolonged use } \\
\text { of steroids in COVID } \\
\text { hospital }\end{array}$ & $\begin{array}{c}\text { Endoscopic surgical } \\
\text { debridement plus } \\
\text { amphotericin B } \\
\end{array}$ & Cured \\
\hline 3 & 7 & $M$ & Sinonasal & $\begin{array}{l}\text { Facial pain, nasal block, nasal } \\
\text { discharge }\end{array}$ & $\begin{array}{l}\text { Acute lymphoblastic } \\
\text { leukemia }\end{array}$ & $\begin{array}{c}\text { Endoscopic surgical } \\
\text { debridement plus } \\
\text { amphotericin B } \\
\end{array}$ & Cured \\
\hline 4 & 10 & $M$ & Oronasal & $\begin{array}{c}\text { Facial pain, palatal black } \\
\text { eschar, nasal discharge, nasal } \\
\text { block }\end{array}$ & $\begin{array}{l}\text { Uncontrolled } \\
\text { diabetes }\end{array}$ & $\begin{array}{l}\text { Endoscopic surgical } \\
\text { debridement plus } \\
\text { amphotericin B }\end{array}$ & Cured \\
\hline 5 & 11 & $\mathrm{~F}$ & Sinonasal & $\begin{array}{l}\text { Facial pain, nasal discharge, } \\
\text { nasal block }\end{array}$ & $\begin{array}{l}\text { Non-Hodgkin's } \\
\text { lymphoma }\end{array}$ & $\begin{array}{c}\text { Endoscopic surgical } \\
\text { debridement plus } \\
\text { amphotericin B }\end{array}$ & $\begin{array}{l}\text { Death due to } \\
\text { respiratory } \\
\text { failure }\end{array}$ \\
\hline 6 & 12 & $\mathrm{~F}$ & $\begin{array}{l}\text { Naso-orbital- } \\
\text { cerebral }\end{array}$ & $\begin{array}{l}\text { Facial swelling, headache, } \\
\text { altered sensorium, proptosis, } \\
\text { nasal discharge, nasal block }\end{array}$ & $\begin{array}{c}\text { Prolonged use } \\
\text { of steroids in COVID } \\
\text { hospital }\end{array}$ & $\begin{array}{c}\text { Endoscopic surgical } \\
\text { debridement plus } \\
\text { amphotericin B }\end{array}$ & $\begin{array}{l}\text { Death due to } \\
\text { rapid spread } \\
\text { to brain }\end{array}$ \\
\hline 7 & 12 & M & Naso-orbital & $\begin{array}{l}\text { Headache, orbital pain, nasal } \\
\text { discharge, nasal block }\end{array}$ & $\begin{array}{l}\text { Uncontrolled } \\
\text { diabetes }\end{array}$ & $\begin{array}{c}\text { Endoscopic surgical } \\
\text { debridement plus } \\
\text { amphotericin B } \\
\end{array}$ & Cured \\
\hline 8 & 14 & M & Sinonasal & $\begin{array}{l}\text { Facial swelling, facial pain, } \\
\text { nasal discharge, nasal block }\end{array}$ & $\begin{array}{l}\text { Non-Hodgkin's } \\
\text { lymphoma }\end{array}$ & $\begin{array}{c}\text { Endoscopic surgical } \\
\text { debridement plus } \\
\text { amphotericin B }\end{array}$ & Cured \\
\hline 9 & 15 & M & Naso-orbital & $\begin{array}{c}\text { Facial swelling, facial pain, } \\
\text { proptosis, nasal discharge, } \\
\text { nasal block }\end{array}$ & $\begin{array}{l}\text { Treated with tocili- } \\
\text { zumab }\end{array}$ & $\begin{array}{l}\text { Endoscopic surgical } \\
\text { debridement plus } \\
\text { amphotericin B }\end{array}$ & Cured \\
\hline 10 & 15 & M & Sinonasal & $\begin{array}{c}\text { Facial swelling, numbness } \\
\text { over face, nasal discharge, } \\
\text { nasal block }\end{array}$ & $\begin{array}{l}\text { Uncontrolled diabe- } \\
\text { tes mellitus }\end{array}$ & $\begin{array}{c}\text { Endoscopic surgical } \\
\text { debridement plus } \\
\text { amphotericin B }\end{array}$ & Cured \\
\hline 11 & 16 & M & Sinonasal & $\begin{array}{l}\text { Headache, Numbness over } \\
\text { face, nasal discharge,nasal } \\
\text { block }\end{array}$ & $\begin{array}{l}\text { Use of systemic } \\
\text { steroids }\end{array}$ & $\begin{array}{c}\text { Endoscopic surgical } \\
\text { debridement plus } \\
\text { amphotericin B }\end{array}$ & Cured \\
\hline 12 & 16 & $\mathrm{~F}$ & Naso-orbital & $\begin{array}{l}\text { Headache, nasal discharge, } \\
\text { nasal block }\end{array}$ & No co-morbidity & $\begin{array}{c}\text { Endoscopic surgical } \\
\text { debridement plus } \\
\text { amphotericin B }\end{array}$ & Cured \\
\hline
\end{tabular}

pneumonia during treatment at COVID hospital. Patient follow-up was done after 6 months' interval after surgery.

\section{DISCUSSION}

The current COVID-19 pandemic originated in Wuhan, China, in December 2019 and became global pandemic because of its rapid spread [5]. The spectrum of clinical presentations of symptomatic COVID-19 patient ranges from mild to critical [6]. COVID-19 patients usually show higher levels of inflammatory cytokines (interleukin (IL)-2R, IL-6, IL-10 and tumour necrosis factor-alpha), impaired cell-mediated immune response, affect both CD4+ T and CD8+ T cells [7, 8]. COVID-19 patients often treated with steroids and immunomodulators which impair the immune system of the patient. So,
COVID-19 patients have susceptibility towards fungal co-infections such as mucormycosis [9]. Mucormycosis is a rare, fatal, angio-invasive and opportunistic fungal infection among children which can affect any organ of the body [10]. In the head and neck region, rhino-orbital-cerebral infection is common type of the mucormycosis infections [11]. The mucormycosis infection accounts for approximately $10 \%$ of all mycotic infections [12]. Although immune deficiency is an important risk factors for co-fungal infections, there are several other diseases also provide chance for mucormycosis in children. Hematological malignancy is an important risk factor for mucormycosis [13]. In one study, the incidence of mucormycosis among children with acute lymphoblastic leukemia (ALL) was 2.2\% [14]. Acute lymphoblastic leukemia and increasing age were two important risk 
factors for developing mucormycosis [14]. In our study, $16.66 \%$ of the children were diagnosed with acute lymphoblastic leukemia. Other risk factors are hematopoietic stem cell transplants or solid organ transplant recipient. Solid organ cancer (without transplant) is not usually associated with mucormycosis [15]. Diabetes mellitus is also another important risk factor with $9 \%$ to $36 \%$ of the cases of mucormycosis found in diabetes [16]. In our study, 25\% cases were diabetic. Injudicious use of steroids during treatment of COVID-19 infections lower the immunity is also an important risk factor for getting mucormycosis infection. Systemic steroid not only lowers the immunity and but also increases the blood glucose level in the blood and so act as risk for getting fungal infection [5]. In this study, $25 \%$ of the children were taking systemic steroid for longer period. In some children, no specific underlying risk factors are associated with mucormycosis [17]. In our study, one (8.33\%) patient had taken tocilizumab during the treatment of the COVID-19 infection. Tocilizumab is an immunomodulator which impair the immunity of the patient. In our study, one case $(8.33 \%)$ had no risk factors for causing mucormycosis. Iron overload, deferoxamine therapy, intravenous drug use, kidney diseases are less common in children but remain well recognized risk factors for causing mucormycosis in children [18]. Burns and traumatic ulcers/ wounds may be associated with cutaneous mucormycosis [18].

The diagnosis of the CAM may be hampered by their non-specific symptoms and signs such as bloody nasal discharge, facial swelling, facial pain, conjunctival suffusion, blurry vision which may mimic to common infectious etiologies [19]. The important point behind successful management is early identification, elimination of the predisposing factors, aggressive surgical debridement and infusion of systemic antifungal agents. Diagnosis may be delayed because of its non-specific clinical manifestation. Timely diagnosis is the key behind the prompt treatment of the CAM in children. Clinical suspicion and early diagnosis with prompt treatment are key steps for preventing the morbidity and mortality of this dreaded clinical condition like rhino-orbital-cerebral mucormycosis [20]. Proper history taking, physical examination and imaging are key component for diagnosis of the suspected mucormycosis. In CAM, computed tomography (CT) scan will often reveal the bone destruction. Brain magnetic resonance imaging (MRI) is helpful to rule out any intracranial or orbital involvement [21]. MRI of the brain may show multiple areas of infarction and ischemia indicating invasive fungal disease. In case of unstable hemodynamic and poor respiratory status with inability to keep the patient in supine position without oxygen desaturation made unfeasibility for performing MRI. Bedside diagnostic nasal endoscopy can be done in a timely manner and histopathological processing in case of active COVID-19 infection are useful for starting

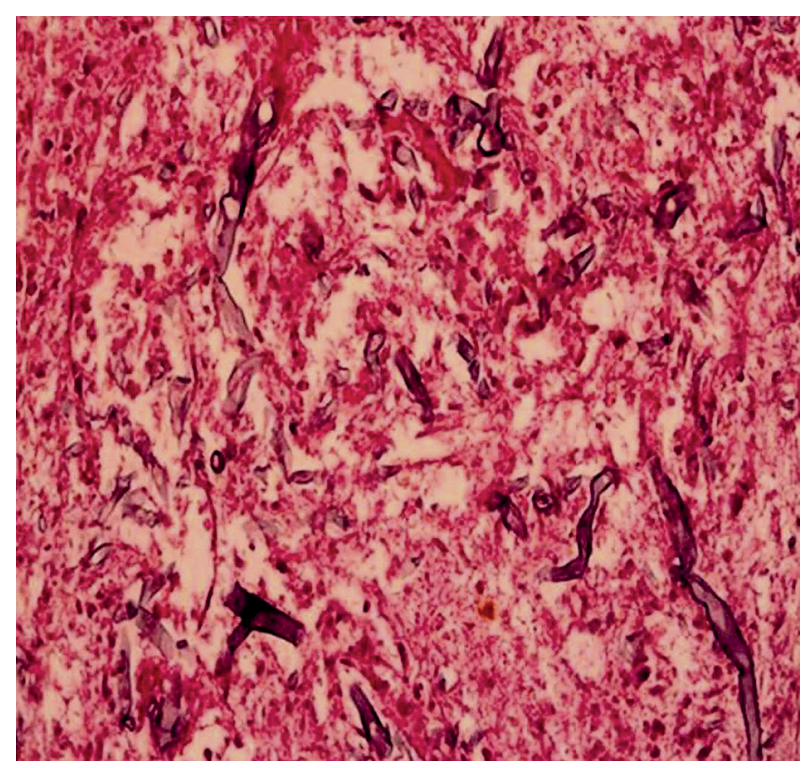

FIGURE 1. Histopathology microphotograph showing broad nonseptate hyphae with $90^{\circ}$ branching (eosin stain and $400 \times$ magnification)

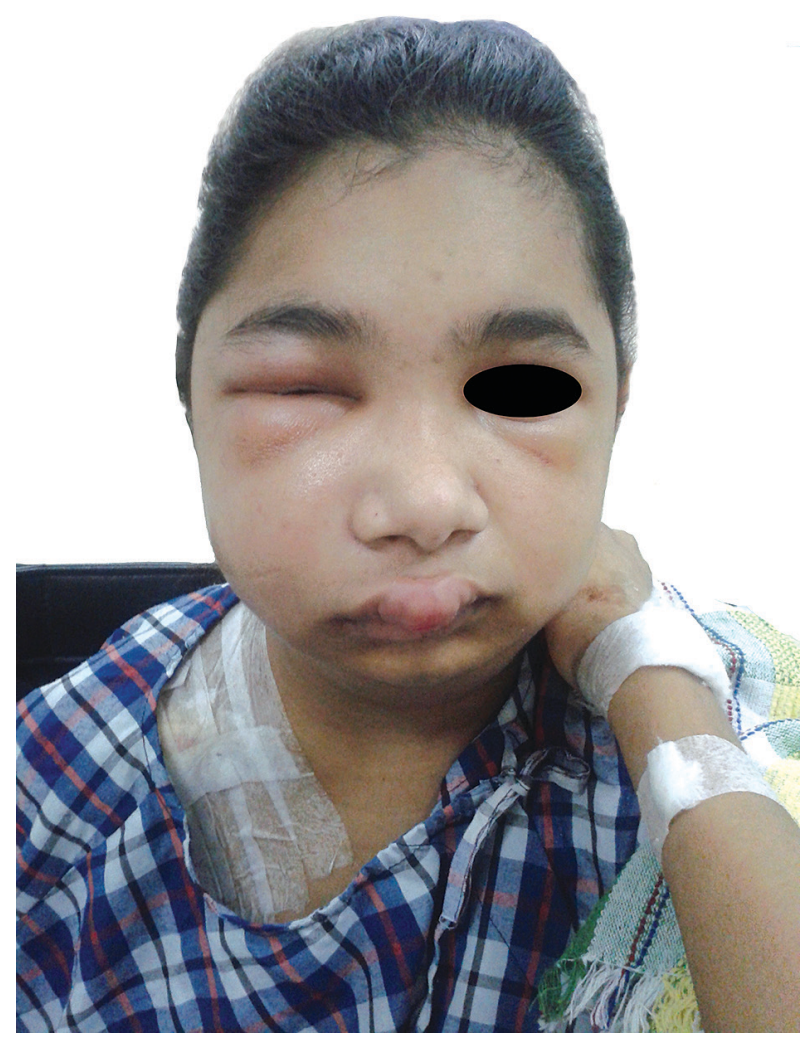

FIGURE 2. A 12-year-old girl of CAM presenting right side facial and orbital swelling

the treatment for rhino-orbital mucormycosis. Mucor is usually demonstrated via a nasal biopsy and subsequent culture. Tissue is sent for histopathological examination and $\mathrm{KOH}$ mount which confirm the mucormycosis [22]. Fresh tissue examination with $\mathrm{KOH} / \mathrm{Cal}$ cofluor-white is helpful to establish a rapid diagnosis. Frozen section is shortening the time of the diagnosis and improving 
the outcome this dreaded infection. Direct microscopy, histopathology and culture from the clinical samples are the major diagnostic modalities for the mucormycosis [23].

Mucormycosis requires an urgent intervention, because of rapid progression and destructive nature of this infection [24]. Delayed initiation of treatment results in higher chance of mortality. Aggressive surgical debridement of the necrotic tissue till getting healthy bleeding tissue is useful for better drug penetration to the affected sites. Histopathological examination post-operatively are advised to ensure complete clearance of the lesion. The standard medical treatment for CAM is amphotericin $B$ in a dose of 1-1.5 mg/kg/day for weeks to months on the basis of the clinical response [25]. However, the exact duration of the treatment is not well established [26]. The less toxic type of amphotericin B is liposomal form, colloidal dispensable form and lipid complex are administrated in greater dose $(3-5 \mathrm{mg} / \mathrm{kg} /$ day with little side effects. Topical use of amphotericin B is also useful but it has limited availability and high cost. Posaconazole is an important alternative antifungal drug but is its use has not been established in pediatric age group [25]. In few selected patients of mucormycosis, hyperbaric oxygen is helpful [26]. In this study, a combined endoscopic surgical debridement and medical treatment with amphotericin B was the mainstay of the treatment. Antifungal treatment is usually insufficient to cure mucormycosis as angioinvasion and thrombosis of the vessels in mucormycosis prevent optimal penetration of the antifungal agents to the site of infection. Surgical debridement of the infected necrotic tissue is usually required along with systemic antifungal agents [27].

Despite intensive use of broad-spectrum antifungal and adequate surgical debridement, the mortality rate of these patients is more than $40 \%$ since many decades [28]. The mortality rate in the pediatric patients of CAM is high, particularly in immunocompromised children. The high mortality in pediatric patients with CAM is associated with untreated cases, disseminated infection at age less than one year [29]. A study showed six cases of invasive mucormycosis during treatment of malignancies where all received liposomal amphotericin B and four received surgical excision along with antifungal treatment and two of them died where 1 (17\%) was due to mucormycosis [30]. The outcome of invasive mucormycosis in non-transplant children resulted in approximately $90 \%$ success rate [31]. The use of liposomal amphotericin B contributed to positive outcome and survival in invasive mucormycosis. Invasive opportunistic fungal diseases are very important causes for morbidity and mortality in children with cancer and those with allogenic haemopoietic stem cell transplantation [32]. Apart from different underlying comorbidities in adult age group, invasive fungal diseases like mucormycosis in infants, children and adolescents are unique with respect to epidemiology, diagnostic tech- niques, pharmacology and dosing antifungal medications absence of phase 3 clinical trials for evidence based decisions [32].

Poor oral hygiene during oxygen administration and use of unsterile, unclean oxygen providing medical devices are also responsible for co-fungal infections to the COVID-19 children. So, the oral care should be done and devices giving oxygen must be maintained with optimum sterility [11]. High index of clinical suspicion, early diagnosis and prompt treatment can improve the survival of the children. Sometimes the diagnosis is delayed by the clinicians those are not much familiar to this disease COVID-19 children with mucormycosis.

\section{CONCLUSIONS}

Mucormycosis is a fatal fungal infection resulting in vascular invasion by the hyphae leading to thrombosis and necrosis of the host tissue. Paediatric patients of haematological malignancies, diabetes mellitus or taking systemic steroids or under any immunosuppressive medication with COVID-19 infection are at higher susceptibility to mucormycosis. In COVID-19 children, the severity of the mucormycosis is due its rapid progression and angio-invasive nature. Paediatrician or paediatric otorhinolaryngologists should act promptly to identify the mucormycosis particularly in immunocompromised children. The widely accepted treatment for mucormycosis is amphotericin B along with surgical debridement. The rising of mucormycosis or black fungus in COVID-19 paediatric patients can be managed effectively if identified early with adequate treatment with amphotericin B, surgical debridement and controlling of the associated risk factors.

\section{STUDY LIMITATION}

This study has a relatively small sample size and may limit the outcome of the above interpretation. However, the outcome of this study will definitely encourage the future research work in this fatal clinical entity called COVID-19 associated mucormycosis.

\section{DISCLOSURE}

The authors declare no conflict of interest.

\section{REFERENCES}

1. Zaoutis TE, Roilides E, Chiou CC, etc. Zygomycosis in children: a systematic review and analysis of reported cases. Pediatr Infect Dis J 2007; 26: 723-727.

2. Yang X, Yu Y, Xu J, et al. Clinical course and outcomes of critically ill patients with SARS-CoV-2 pneumonia in Wuhan, China: a single-centered, retrospective, observational study. The Lancet Respiratory Medicine 2020; 8: 475-481. 
3. Swain SK, Jena PP. Clinical implications and future perspective of COVID-19 pandemic - a review. Int J Adv Med 2021; 8: 334-340.

4. Zhou P, Yang XL, Wang XG, et al. A pneumonia outbreak associated with a new coronavirus of probable bat origin. Nature 2020; 579: 270-273.

5. Velavan TP, Meyer CG. The COVID-19 epidemic. Trop Med Int Health 2020; 25: 278-280.

6. Broughton JP, Deng X, Yu G, et al. CRISPR - Cas12-based detection of SARS-CoV-2. Nat Biotechnol 2020; 38: 870-874.

7. Swain SK, Acharya S, Sahajan N. Otorhinolaryngological manifestations in COVID-19 infections: An early indicator for isolating the positive cases. J Sci Soc 2020; 47: 63-68.

8. Swain SK, Das S, Padhy RN. Performing tracheostomy in intensive care unit-A challenge during COVID-19 pandemic. Siriraj Medical Journal 2020; 72: 436-442.

9. Song G, Liang G, Liu W. Fungal co-infections associated with global COVID-19 pandemic: a clinical and diagnostic perspective from China. Mycopathologia 2020; 185: 599-606.

10. Rodden M, Zaoutis T, Buchanan W, et al. Epidemiology and outcome of zygomycosis: a review of 929 reported cases. Clin Infect Dis 2005; 41: 634-653.

11. Cornely OA, Alastruey-Izquierdo A, Arnez D, et al. Global guideline for the diagnosis and management of mucormycosis:an initiative of the European Confederation of Medical Mycology in cooperation with the Mycoses Study group Education and Research Consortium. Lancet Infect Dis 2019; 19: 405-421.

12. Sharma MC, Gill SS, Kashyap S, et al. Gastrointestinal mucormycosis - an uncommon isolated mucormycosis. Indian J Gastroenterol 1998; 17: 131-133.

13 Swain SK, Lenka S, Das SR. Rhino-orbital Mucormycosis - A Dreaded Clinical Entity. Int J Cur Res Rev 2020; 12: 197-203.

14. Elitzur S, Arad-Cohen N, Barg A, et al. Mucormycosis in children with haematological malignancies is a salvageable disease: a report from the Israeli Study Group of Childhood Leukemia. Br J Haematol 2020; 189: 339-350.

15. Kennedy KJ, Daveson K, Slavin MA, et al. Australia and New Zealand Mycoses Interest Group of the Australasian Society for Infectious Diseases. Mucormycosis in Australia: contemporary epidemiology and outcomes. Clin Microbiol Infect 2016; 22: 775-781.

16. Skiada A, Pagano L, Groll A, et al; European Confederation of Medical Mycology Working Group on Zygomycosis. Zygomycosis in Europe: analysis of 230 cases accrued by the registry of the European Confederation of Medical Mycology (ECMM) Working Group on Zygomycosis between 2005 and 2007. Clin Microbiol Infect 2011; 17: 1859-1867.

17. Pana ZD, Seidel D, Skiada A, et al. Collaborators of Zygomyco.net and/or FungiScope Registries. Invasive mucormycosis in children: an epidemiologic study in European and non-European countries based on two registries. BMC Infect Dis 2016; 16: 667.

18. Petrikkos G, Skiada A, Lortholary O, et al. Epidemiology and clinical manifestations of mucormycosis. Clin Infect Dis 2012; 54: 23-34.

19. Swain SK, Behera IC, Mohanty JN. Mucormycosis in head-andneck region - Our experiences at a tertiary care teaching hospital of Eastern India. Annals of Indian Academy of Otorhinolaryngology Head and Neck Surgery 2019; 3: 58-62.

20. Swain SK, Sahu MC, Banerjee A. Non-sinonasal isolated facio-orbital mucormycosis - A case report. J Mycol Med 2018; 28: 538-541.

21. Sen M, Honavar SG, Sharma N, Sachdev MS. COVID-19 and Eye: A Review of Ophthalmic Manifestations of COVID-19. Indian J Ophthalmol 2021; 69: 488-509.

22. Swain SK, Sahu MC, Baisakh MR. Mucormycosis of the Head and Neck. Apollo Medicine 2018; 15: 6-10.
23. Spellberg B, Edwards J, Ibrahim A. Novel perspectives on mucormycosis: pathophysiology, presentation, and management. Clin Microbiol Rev 2005; 18: 5.

24. Prakash H, Ghosh AK, Rudramurthy SM, et al. A prospective multicenter study on mucormycosis in India:epidemiology, diagnosis and treatment. Med Mycol 2019; 57: 395-402.

25. Lumbang WA, Caufield BA. Vesicular eruption on the arm of an infant. Dermatol Online J 2010; 16: 13.

26. Sandeep P, Dave MD, Richard J, et al. Facial cutaneous mucormycosis in a full-term infant. Arch Otolaryngol Head Neck Surg 2008; 134: 206-209.

27. Khan ZU, Ahmad S, Brazda A, et al. Mucor circinelloides as a cause of invasive maxillofacial zygomycosis: an emerging dimorphic pathogen with reduced susceptibility to pasoconazole. J Clin Microbiol 2009; 47: 1244-1248.

28. Abedi E, Sismanis A, Choi K, et al. Twenty-five years' experience treating cerebro-rhino-orbital mucormycosis. Laryngoscope1984; 94: 1060-1062.

29. Werthman-Ehrenreich A. Mucormycosis with orbital compartment syndrome in a patient with COVID-19. Am J Emerg Med 2021; 42: 264.e5-264.e8.

30. Antoniadi K, Iosifidis E, Vasileiou E, et al. Invasive Mucormycosis in Children With Malignancies: Report From the Infection Working Group of the Hellenic Society of Pediatric Hematology-Oncology. Chemotherapy 2020; 2: 5-15.

31. Styczynski J, Czyżewski K, Frączkiewicz J, et al. Clinical spectrum and outcome of invasive mucormycosis in children and adults: Polish experience of the decade 2010-2019. Acta Haematol Pol 2020; 51: 157-163.

32. Groll AH, Castagnola E, Cesaro S, et al. Fourth European Conference on Infections in Leukaemia; Infectious Diseases Working Party of the European Group for Blood Marrow Transplantation (EBMT-IDWP); Infectious Diseases Group of the European Organisation for Research and Treatment of Cancer (EORTC-IDG); International Immunocompromised Host Society (ICHS); European Leukaemia Net (ELN). Fourth European Conference on Infections in Leukaemia (ECIL-4): guidelines for diagnosis, prevention, and treatment of invasive fungal diseases in paediatric patients with cancer or allogeneic haemopoietic stem-cell transplantation. Lancet Oncol 2014; 15: 327-340. 